\title{
Improved diagnosis of reactivated toxoplasmosis
}

\author{
D Ashburn, M M Davidson, A W L Joss, T H Pennington, D O Ho-Yen
}

\begin{abstract}
Aims-To identify antigens detected by western blotting in primary Toxoplasma gondii infection and determine their role in diagnosis of reactivated toxoplasmosis. Methods-Twenty three immunocompromised patients were tested by IgG western blotting. Patients were grouped retrospectively. Group 1 comprised 15 human immunodefiency (HIV)/AIDS patients and included: group 1A (six patients with clinical and/or serological evidence of reactivation), group $1 \mathrm{~B}$ (five patients with clinical evidence only), and group 1C (four asymptomatic patients). Group 2 comprised eight non-HIVIAIDS immunocompromised patients with clinical and/or serological evidence of reactivation. Immunocompetent patients $(n=23)$ with primary toxoplasmosis were a control group used to determine the progression of the antigens detected.
\end{abstract}

Results-In primary toxoplasmosis, antibodies against $6,20,22,23,25,28,29$, and $36 \mathrm{kDa}$ antigens predominated. Detection of four or more of the $6,20,22,23,25$, and $36 \mathrm{kDa}$ antigens was considered to be western blot positive. In two group 1A patients, western blotting indicated past infection. During reactivation, this reverted to being western blot positive. Three other group 1A patients were western blot positive. In three of five group 1B patients, western blot positive results improved serological diagnosis of reactivated toxoplasmosis $(p<0.05)$. In two of five group 1B patients and all four group 1C patients, western blot indicated past infection. In group 2 , two of eight patients reverted from a pattern of past infection to western blot positive. Five other patients from group 2 were western blot positive.

Conclusions-Detection of some low molecular weight antigens is diagnostic of reactivated toxoplasmosis. These antigens can be detected even with normal dye test titres and their detection improves the diagnosis of reactivated toxoplasmosis. They might be the result of the release of bradyzoites from ruptured tissue cysts. (f Clin Pathol: Mol Pathol 1998;51:105-109)

Keywords: primary toxoplasmosis; reactivated toxoplasmosis; western blotting

Toxoplasma gondii infection in the immunocompromised patient can be severe and even fatal. ${ }^{1}$ Although infection can be primary, in human immunodeficiency virus (HIV)/AIDS patients, more than $95 \%$ of toxoplasma encephalitis is caused by reactivation of a latent infection. ${ }^{2}$ Following infection, $T$ gondii undergoes asexual reproduction that culminates in the formation of tissue cysts, which persist for the life of the host. ${ }^{2-5}$ In the immunocompetent host, immunity is usually sufficient to contain the latent infection and thereby limit the disease. ${ }^{3}$ When host defences are impaired, owing to HIV infection, malignancy, or immunosuppressive drugs, reactivated toxoplasmosis occurs because tissue cysts rupture and release the active bradyzoite, which results in clinical disease. ${ }^{6}$

Serodiagnosis of reactivated toxoplasmosis is difficult. Toxoplasma specific IgG may not be detected in up to $3 \%$ of HIV/AIDS patients with reactivated toxoplasmosis. ${ }^{2}$ In addition, detection of toxoplasma specific IgG does not distinguish current from past infection, ${ }^{7}$ and the acute episode of reactivated toxoplasmosis may not be associated with a significant change in titre. ${ }^{2-4}$ In primary toxoplasmosis, detection of specific IgM indicates acute infection, ${ }^{8}$ but in reactivated toxoplasmosis, this too is frequently not detectable. ${ }^{2-4}$ Therefore, diagnosis is often based on a combination of epidemiological, clinical, and radiological data. ${ }^{9}$

IgG western blotting in HIV/AIDS patients failed to demonstrate antigens associated with reactivated toxoplasmosis, ${ }^{11}{ }^{11}$ but predominantly high molecular weight antigens were examined in both of these studies. We have demonstrated previously the importance of detecting antibodies against low molecular weight antigens in primary toxoplasmosis. ${ }^{12}$ Therefore, the current study examined the detection of such antibodies in the diagnosis of reactivated toxoplasmosis in HIV/AIDS patients and in non-HIV/AIDS immunocompromised patients.

\section{Methods}

Fifty six serum samples from 23 immunocompromised patients investigated for reactivated toxoplasmosis were tested for $T$ gondii specific IgG and $\operatorname{IgM}$ antibodies using in-house enzyme linked immunosorbent assays (ELISAs). ${ }^{13}{ }^{14}$ Results were confirmed using a micromodification of the dye test $\mathrm{t}^{15}$ and a commercial IgM capture ELISA (Toxonostika ELISA-IgM; Organon Teknika, Cambridge, UK). A third more sensitive IgM assay (ToxoISAGA; BioMerieux, Marcy L'Etoile, France) was used to test sera that were negative by one or both ELISA IgM methods. The control group was 23 patients ( 28 sera) diagnosed with primary toxoplasmosis. These were used to establish the progression of antigens recognised during primary toxoplasmosis.

The patients were grouped retrospectively, according to whether they were HIV/AIDS or non-HIV/AIDS immunocompromised, and
Accepted for publication 27 January 1998 
Table 1 Progression of antigens detected in primary Toxoplasma gondii infection

\begin{tabular}{|c|c|c|c|c|c|c|c|c|c|c|c|c|c|}
\hline \multirow{2}{*}{$\begin{array}{l}\text { Time since onset of } \\
\text { symptoms (weeks) }\end{array}$} & \multirow[b]{2}{*}{$n$} & \multicolumn{12}{|c|}{ Molecular weight ( $k D a$ ) of antigen (number of times antigens detected) } \\
\hline & & 6 & 20 & 22 & 23 & 25 & 27 & 28 & 29 & 31 & 32 & 34 & 36 \\
\hline$<4$ & 6 & 2 & 1 & 3 & 3 & 3 & 1 & 6 & 5 & - & - & 2 & 2 \\
\hline $5-16$ & 8 & 6 & 5 & 5 & 6 & 5 & 1 & 7 & 7 & 3 & 3 & 4 & 6 \\
\hline $17-36$ & 14 & 8 & 8 & 12 & 12 & 13 & 3 & 14 & 14 & 9 & 9 & 9 & 12 \\
\hline Past infection ${ }^{\star}$ & 10 & 5 & - & - & - & - & - & 5 & 5 & 8 & 6 & 8 & 1 \\
\hline
\end{tabular}

^Data from reference 12 .

according to clinical (cerebral lesions, response to treatment) and serological evidence of reactivated toxoplasmosis. Group 1 comprised 15 HIV/AIDS patients (33 sera) and was subdivided into three further groups. Group 1A comprised six patients with clinical (two patients) and/or serological (six patients) evidence of reactivated toxoplasmosis; group $1 \mathrm{~B}$ comprised five patients with clinical but no serological evidence of reactivated toxoplasmosis; and Group 1C comprised four asymptomatic patients. Group 2 comprised eight non-HIV/AIDS patients (23 sera) (four leukaemia, two other malignancy, two on immunosuppressive treatment). There was serological evidence of reactivated toxoplasmosis in all eight of these patients, but clinical information was available for only two (confusion and fever in one patient, cerebral lesions in the second).

Western blotting was performed as described previously. ${ }^{12}$ Briefly, antigen was prepared using toxoplasma tachyzoites harvested from the peritoneal cavities of cotton rats infected 66 hours previously. Antigen was washed with sterile, normal saline, frozen and thawed, sonicated, and then mixed with an equal volume of lysis buffer containing 4\% lauryl sulphate and $2 \% 2$-mercaptoethanol. Antigen was stored at $-20^{\circ} \mathrm{C}$ until use. Proteins were separated by sodium dodecyl sulphate polyacrylamide gel electrophoresis (SDS-PAGE), ${ }^{16}$ using a $15 \%$ polyacrylamide separation gel with a $3 \%$ stacking gel. Antigen was boiled for five minutes and $125 \mu \mathrm{l}$ was applied evenly to the entire length of a single well, $125 \mathrm{~mm}$ long. In two separate lanes, a mixture of molecular weight markers, either prestained (Sigma Chemical Company Ltd, Poole, Dorset, UK) or unstained (Sigma dalton mark V11-L), was added. Gels were electrophoresed overnight at $8 \mathrm{~mA} / \mathrm{gel}$. Proteins were transferred on to a nitrocellulose membrane in an LKB Transphor immunoblotter at $300 \mathrm{~mA} /$ gel for four hours at room temperature. The nitrocellulose membranes were blocked using 5\% non-fat dried milk in

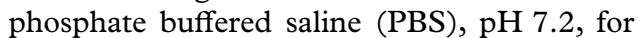
one hour, rinsed with PBS, dried, and stored in the dark at room temperature until use. The membranes were cut into strips $\sim 3 \mathrm{~mm}$ wide, incubated overnight with human serum diluted $1 / 50$ in $5 \%$ non-fat milk in PBS $/ 0.05 \%$ Tween 20 (PBST), washed with five changes of PBST, and incubated for two hours at room temperature with conjugate (Sigma; goat antihuman IgG peroxidase) diluted $1 / 1000$ in $5 \%$ non-fat milk in PBST. After four washes with PBST and one with PBS alone, the substrate was added $(0.06 \%$ 4-chloro-naphthol in methanol, $0.014 \%$ hydrogen peroxide in PBS). After 10 minutes, the strips were washed twice with PBST, twice with distilled water, and dried.

\section{Results}

In the control group, raised dye test titres were measured and specific IgM was confirmed positive in all sera. The time since the onset of symptoms was known for each patient. This ranged from 1 to 36 weeks and was consistent with the serological results. Using western blotting, antigens with molecular weights between 6 and 116 kilodaltons $(\mathrm{kDa})$ were identified. No bands were seen in a $T$ gondii specific antibody negative control serum. A $15 \%$ polyacrylamide separation gel was used to improve separation of low molecular weight antigens and, therefore, only antigens $<37 \mathrm{kDa}$ were studied in detail.

Table 2 Antigens recognised in sera from immunocompromised patients in past and reactivated infection

\begin{tabular}{|c|c|c|c|c|c|c|c|c|c|c|c|c|c|c|c|c|c|}
\hline \multirow[b]{2}{*}{$\begin{array}{l}\text { Patient } \\
\text { (Group) }\end{array}$} & \multirow[b]{2}{*}{ Clinical details } & \multirow[b]{2}{*}{$\begin{array}{l}\text { Specimen } \\
\text { date }\end{array}$} & \multirow[b]{2}{*}{$\begin{array}{l}\text { Dye test } \\
\text { (IU/ml) }\end{array}$} & \multicolumn{2}{|c|}{ Serology } & \multicolumn{12}{|c|}{ Antigen $(k D a)$} \\
\hline & & & & $\begin{array}{l}\text { ELISA } \\
\text { IgM }\end{array}$ & $\begin{array}{l}\text { ISAGA } \\
\text { IgM }\end{array}$ & 6 & 20 & 22 & 23 & 25 & 27 & 28 & 29 & 31 & 32 & 34 & 36 \\
\hline \multirow[t]{3}{*}{$1(1 \mathrm{~A})$} & $\begin{array}{l}\text { HIV/AIDS } \\
\text { asymptomatic }\end{array}$ & 31.08 .90 & 65 & - & - & - & - & - & - & - & - & + & + & + & - & - & - \\
\hline & $\mathrm{C}, \mathrm{R}$ & 05.10 .90 & 1000 & + & + & +++ & +++ & ++ & ++ & +++ & + & ++ & ++ & +++ & + & + & ++ \\
\hline & & 06.12 .90 & 250 & - & + & ++ & ++ & + & + & + & - & ++ & ++ & ++ & - & - & ++ \\
\hline \multirow[t]{2}{*}{$2(1 \mathrm{~A})$} & $\begin{array}{l}\text { HIV/AIDS } \\
\text { asymptomatic }\end{array}$ & 27.03 .90 & 65 & - & - & - & - & - & - & - & - & + & + & - & - & - & + \\
\hline & None & 04.10 .90 & 125 & - & + & ++ & ++ & ++ & ++ & ++ & - & ++ & ++ & ++ & - & - & + \\
\hline \multirow[t]{3}{*}{$3(2)$} & $\begin{array}{l}\text { Immunosuppressive } \\
\text { therapy }\end{array}$ & 03.09 .92 & 65 & - & - & - & - & + & + & + & - & + & - & - & - & - & - \\
\hline & & 06.11 .92 & 30 & - & - & - & - & + & + & + & - & - & - & - & - & - & \\
\hline & Confusion, pyrexia & 24.03 .95 & 1000 & - & - & - & +++ & ++ & +++ & ++ & - & ++ & ++ & + & + & + & ++ \\
\hline \multirow[t]{4}{*}{$4(2)$} & $\mathrm{T}$ cell lymphoma & 07.10 .91 & 65 & - & - & - & - & - & - & - & - & + & + & - & - & - & - \\
\hline & & 08.11 .92 & 65 & - & - & - & - & - & - & - & - & + & + & - & - & - & - \\
\hline & None & 15.1.93 & 1000 & - & + & - & + & + & + & ++ & - & + & ++ & - & - & - & + \\
\hline & & 18.2 .93 & 4000 & - & + & + & ++ & ++ & ++ & ++ & + & ++ & ++ & + & - & - & + \\
\hline
\end{tabular}

Serology: - , negative; + , positive.

Relative intensity of staining: - , absent; + , faint; ++ , moderate; +++ , intense

$\mathrm{C}$, cerebral lesions on computed tomography; R, responded to treatment. 
In sera collected within four weeks since the onset of symptoms, antibodies against 28 and $29 \mathrm{kDa}$ antigens predominated (table 1). These continued to be detected until 16 weeks and antibodies against $6,20,22,23,25$, and $36 \mathrm{kDa}$ antigens became more prominent (table 1). Between 17 and 36 weeks after the onset of symptoms, antigens with molecular weights of 31,32 , and $34 \mathrm{kDa}$ were detected with increasing frequency (table 1). Antibodies against 28 and $29 \mathrm{kDa}$ antigens were also detected in past infection, but less frequently. ${ }^{12}$ Instead, antibodies against 31,32 , and $34 \mathrm{kDa}$ antigens predominated (table 1 ).

All sera from the 23 immunocompromised patients were dye test positive. In group $1 \mathrm{~A}$, raised dye test titres were measured in one or more sera from five of six patients. In patient 1 (table 2), samples with raised dye test titres that were confirmed specific IgM positive were preceded by one sample with a normal dye test that was specific $\operatorname{IgM}$ negative by all three methods. In this sample, using western blotting, only antibodies against 28, 29, and $31 \mathrm{kDa}$ antigens were detected. In the later sera, these bands were also present, but with increased intensity (table 2, fig 1). Bands representing $6,20,22,23,25$, and $36 \mathrm{kDa}$ antigens were also stained intensely, and those at 27,32 , and $34 \mathrm{kDa}$ less so (table 2, fig 1). Sequential sera were also available from a second patient in group $1 \mathrm{~A}$. In the first sample from patient 2 , serology was normal and only 28,29 , and $36 \mathrm{kDa}$ antigens were recognised (table 2, fig 1). The dye test was also normal in subsequent sera and $\operatorname{IgM}$ was detected only when the most sensitive method was used (Toxo-ISAGA). However, using western blotting, the intensity of staining of the 28,29 , and $36 \mathrm{kDa}$ bands increased and antigens at 6,20 , $22,23,24$, and $31 \mathrm{kDa}$ were recognised (table 2 , fig 1). The results of patient 2 indicate that some low molecular weight antigens might not be detected in all sera, and some might be detected in sera as a result of past infection. Therefore, detection of four or more of the most intensely stained bands $(6,20,22,23,25$, and $36 \mathrm{kDa}$ ) was considered to be a positive result. Detection of antibodies against the 28, 29 , and $31 \mathrm{kDa}$ antigens could not be included because these were common both in acute and past infection (table 1). Positive western blot results were obtained in sera from three other patients from group 1A: all three had raised dye test titres and two were IgM positive. Bands representing $6,20,22,23$, and $25 \mathrm{kDa}$ antigens were also recognised by sera from one other patient with a raised dye test titre, but their intensity was insufficient to be considered a positive result.

Group 1B comprised five HIV/AIDS patients with clinical evidence of reactivated toxoplasmosis (cerebral lesions and/or response to treatment). All had normal dye test titres $(\leqslant 125 \mathrm{IU} / \mathrm{ml})$ and specific $\mathrm{IgM}$ was not detected by any of the three methods. However, western blot positive results were obtained for three of these five patients (one sided McNemar test, $\mathrm{p}<0.05$, confidence interval -1.55 to 2.75 ). In the remaining two patients
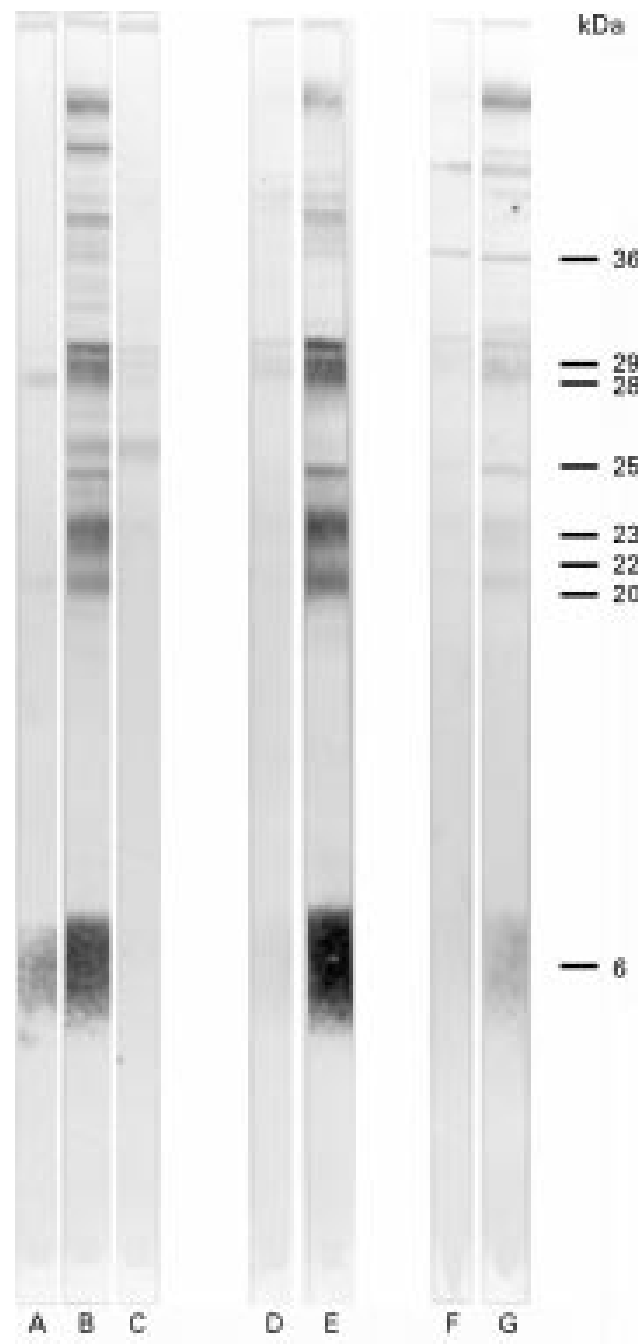

Figure 1 Toxoplasma gondii antigens recognised by antibodies in sera from patients with primary and reactivated toxoplasmosis. Lane A, primary toxoplasmosis (early infection); lane $B$, primary toxoplasmosis (later in (early infection); lane $B$, primary toxoplasmosis (later in
infection); lane $C$, past infection; lane D, patient 1 (dye test normal); lane $E$, patient 1 collected five weeks later, during reactivated infection (raised dye test); lane $F$, patient 2 (normal dye test); lane $G$, patient 2 collected during reactivated infection (normal dye test).

from group $1 \mathrm{~B}$, the western blot pattern was one of past infection. Patients (four) in group $1 \mathrm{C}$ were all asymptomatic. In three of four patients, the dye test titre was normal and specific IgM was negative. In these patients, western blotting indicated past infection, confirming the other results. In the fourth patient, the dye test titre was normal and both ELISA IgM methods were positive; however, these may have been false positives because the ToxoISAGA test was negative. Western blotting indicated past infection but this may have resulted from the low dye test titre $(15 \mathrm{IU} / \mathrm{ml})$ and was not reliable enough to confirm the IgM positive results.

Group 2 comprised eight non-HIV/AIDS immunocompromised patients. Serial specimens were tested from two patients (patients 3 and 4). Both had past infection as determined by stable dye test titres, specific IgM negative, and western blotting (table 2). Subsequently, both had raised dye test titres and one (patient 4) was IgM positive by ELISA. Faint bands 
representing 22, 23, and $25 \mathrm{kDa}$ antigens were present in sera from patient 3 , even when the dye test titre was normal. These and other bands were more intense after the dye test titre increased (table 2). In patient 4 , only bands of 28 and $29 \mathrm{kDa}$ were detected in the first serum sample, but this also reverted to a western blot positive pattern in subsequent sera. Western blot positive patterns were obtained in five other patients from group 2. This corresponded to raised dye test titres and IgM positive results in five of five and four of five patients, respectively. The last patient had a normal dye test titre but IgM was detected by ELISA. Only three low molecular weight antigens $(6,23$, and $36 \mathrm{kDa})$ were recognised, thus failing to meet the criteria for a western blot positive result.

\section{Discussion}

Identification of the toxoplasma antigens that are important in primary toxoplasmosis should enable improved diagnosis of reactivated toxoplasmosis in immunocompromised patients. Whereas other workers have measured primarily high molecular weight antigens, ${ }^{17}{ }^{18}$ previously we have observed differences in the detection of low molecular weight antigens. ${ }^{12}$ Antigens of 28,29 , and $36 \mathrm{kDa}$ were recognised by antibodies in 10 of 10 , nine of 10 , and nine of 10 patients with acute infection, respectively; they were also recognised in five of 10 , four of 10 , and one of 10 patients with past infection, respectively. ${ }^{12}$ Therefore, their presence cannot be regarded as diagnostic of acute infection. Detection of a $6 \mathrm{kDa}$ antigen has also been suggested to be an indicator of acute infection, ${ }^{12}{ }^{19}{ }^{20}$ but because it was recognised in five of 10 sera from patients with past infection ${ }^{12}$ it too might not be specific. Antigens of 22-25 kDa were also recognised by nine of 10 patients with acute infection. ${ }^{12}$ In the present study, these antigens were separated more clearly and antigens at 20,22, 23, and $25 \mathrm{kDa}$ could be recognised. These were detected in 14 of 28,20 of 28,21 of 28 , and 21 of 28 sera, respectively, from patients with acute infection. Differences could also be a result of inaccuracies in the timing of specimens. Nevertheless, in the previous study, ${ }^{12}$ the 22-25 kDa antigens were not recognised in any sera from patients with past infection. This suggests that these antigens may be specific to acute infection.

In reactivated toxoplasmosis, recognition of antigens with molecular weights $18-180 \mathrm{kDa}$ has been examined. ${ }^{10}{ }^{11}$ In one study, ${ }^{10}$ antigens with molecular weights $26-38 \mathrm{kDa}$ were recognised by antibodies in the sera of HIV/AIDS patients, both with or without reactivated toxoplasmosis. However, as there was no pattern that was characteristic of acute infection, ${ }^{10}$ presence of these antigens was not used to diagnose reactivated toxoplasmosis. In our study, antibodies were detected against 6,20 , $22,23,25$, and $36 \mathrm{kDa}$ antigens in 15 of 19 patients with reactivated toxoplasmosis, an antigen recognition pattern similar to that seen in acute primary toxoplasmosis. Unlike a previous study, ${ }^{10}$ our work included some sera collected before and during the period of illness. In four patients (two HIV/AIDS and two non-HIV/AIDS patients), an antigen recognition pattern seen in past toxoplasmosis reverted to one similar to acute primary toxoplasmosis. In particular, sera from patient 1 , collected before illness, had an antigen recognition pattern characteristic of past infection. Demonstration of bands representing 6 , $22,23,25$, and $36 \mathrm{kDa}$ antigens in sera collected five weeks later coincided with a significant change in dye test titre, detection of specific $\operatorname{IgM}$, and a worsening clinical condition. A similar reversion was observed in sera collected from patient 3, and this also corresponded with clinical deterioration and an increase in dye test titre, but specific IgM was not detected. Longitudinal studies of sera collected before and during episodes of reactivated toxoplasmosis have been performed by other workers. ${ }^{11}$ However, the differences in the antigens recognised were attributed to strain variation. ${ }^{11}$ Thus, contrary to previous studies, ${ }^{10}{ }^{11}$ our results indicate that there is an antigen recognition pattern characteristic of reactivated toxoplasmosis. No clinical information was available for the other two patients in whom the reversion western blot was demonstrated and, although it is possible that the reversion accompanied clinical changes, this cannot be confirmed.

The number and intensity of bands detected by western blotting corresponds to the dye test titre. ${ }^{12}$ Therefore, changes in antigen recognition may be attributed to differences in titre between sequential sera. In our study, the intensity of the 28 and $29 \mathrm{kDa}$ bands increased between sequential sera from immunocompromised patients, reflecting the increase in dye test titre. However, because these antigens are also recognised in past infection, ${ }^{12}$ their detection is not indicative of reactivated toxoplasmosis. The relative increase in intensity of the 6 , $20,22,23,25$, and $36 \mathrm{kDa}$ bands was greater than that of the 28 and $29 \mathrm{kDa}$ bands. Increases in the intensity of low molecular weight bands were seen in patient 2 , but without a corresponding increase in dye test titre, whereas the intensity of staining of bands representing high molecular weight antigens changed little between past and reactivated infection. This suggests that changes are not a factor of the dye test titre alone. Instead, this demonstrates the heterogeneity of antibodies detected even when dye test titres are identical, ${ }^{11}$ and that the detection of some low molecular weight antigens is diagnosic of reactivated toxoplasmosis.

Elevated dye test titres have been found to precede the first clinical and radiological signs of toxoplasma encephalitis in HIV/AIDS patients. ${ }^{21}$ Detection of antibodies against low molecular weight antigens, even in sera with a normal dye test, might also be important. This is demonstrated by our observation of western blot positive results in the sera from patients with clinical but no serological evidence of reactivated toxoplasmosis (group 1B). Therefore, a western blot positive result is an 
improvement over other serological techniques.

Re-emergence of antibodies against low molecular weight antigens might be caused by the presence of circulating antigens. ${ }^{11}{ }^{22} \mathrm{Circu}-$ lating antigens have been detected in HIV/ AIDS patients with reactivated toxoplasmosis, and have been found to be highly immunogenic, even in immunocompromised patients. ${ }^{1122}$ Alternatively, antigens with molecular weights $18,{ }^{23} 21,{ }^{23} 23-25,{ }^{2324}$ and $27 \mathrm{kDa}^{19}$ have been shown to be bradyzoite specific, and were apparent four to six weeks after infection. These might correspond to the 20-25 kDa antigens that we detected, perhaps indicating the detection of bradyzoites. This would be consistent with release of bradyzoites from ruptured tissue cysts in reactivated toxoplasmosis. In reactivated cerebral infection, toxoplasma DNA, perhaps from ruptured cysts, might also be detected in blood by the polymerase chain reaction (PCR). ${ }^{125}$ Thus, western blotting and PCR could be used together to optimise diagnosis of reactivated toxoplasmosis; this should be investigated further.

In conclusion, re-emergence of antibodies against the $6,20,22,23,25$, and $36 \mathrm{kDa}$ antigens, common in primary toxoplasmosis, is diagnostic of reactivated toxoplasmosis in immunocompromised patients. Antibodies against these antigens can be detected in patients with a normal dye test titre as well as one which is raised, and is a significant improvement in diagnosis. Low molecular weight antigens might be bradyzoite specific, and detection of antibodies against them might signify release of bradyzoites from ruptured tissue cysts.

We are grateful to Ms D Gilham for her secretarial assistance, and to Mr J McGhee and Mr A MacLeister of the medical illustration department for their help in producing fig 1 . In addition, we thank users of the Scottish Toxoplasma Reference Laboratory for their continuing support. This work was funded by the Scottish Home and Health Department (grant no. K/MRS/50/C1828).

1 Wong SY, Remington JS. Biology of Toxoplasma gondii AIDS 1993; 7:299-316.

2 Luft BJ, Remington JS. Toxoplasmic encephalitis in AIDS Clin Infect Dis 1992;15:211-22.

3 Israelski DM, Remington JS. Toxoplasmic encephalitis in patients with AIDS. Infect Dis Clin North Am 1988;2:42945 .
4 Israelski DM, Remington JS. Toxoplasmosis in the nonAIDS immunocompromised host. Curr Clin Top Infect Dis AIDS immunocomi

5 Israelski DM, Remington JS. Toxoplasmosis in patients with cancer. Clin Infect Dis 1993;17(suppl 2):S423-35.

6 Ruskin J, Remington JS. Toxoplasmosis in the compromised host. Ann Intern Med 1976;84:193-9.

7 Holliman RE. Recent developments in the diagnosis of tox.

8 Joss AWL Diagnosis. In: Ho-Yen DO, Joss AWL eds. Human toxoplasmosis. Oxford: Oxford University Press, 1992:79-118.

9 Pinon JM, Foudrinier F, Mougeot G, et al. Evaluation of risk and diagnostic value of quantitative assays for antiToxoplasma gondii immunoglobulin A (IgA), IgE, and IgM and analytical study of specific IgG in immunodeficient patients. F Clin Microbiol 1995;33:878-84.

10 Weiss LM, Udem SA, Tanowitz H, et al. Western blot analysis of the antibody response of patients with AIDS and toxoplasma encephalitis: antigenic diversity among toxoplasma strains. F Infect Dis 1988;157:7-13.

11 Hassl A, Aspöck H. Antigens of Toxoplasma gondii recognised by sera of AIDS patients before, during and
after clinically important infections. Int $\mathcal{f}$ Med Microbiol 1990;272:514-25.

12 Moir IL, Davidson MM, Ho-Yen DO. Comparison of IgG antibody profiles by immunoblotting in patients with acute and previous Toxoplasma gondii infection. $f$ Clin Pathol 1991;44:569-72.

13 Joss AWL, Skinner LJ, Chatterton JMW, et al. Toxoplasmosis: effectiveness of enzyme immunoassay screening. Med Lab Sci 1989;46:107-12.

14 Joss AWL, Skinner LJ, Moir IL, et al. Biotin-labelled antigen screening test for toxoplasma IgM antibody. 7 Clin Pathol 1989;42:206-9.

15 Williams KAB, Scott JM, Macfarlane DE, et al. Congenital toxoplasmosis: a prospective survey in the west of Scotland. F Infect 1981;3:219-29.

16 Laemmlli UK. Cleavage of structural proteins during the assembly of the head of bacteriophage T4. Nature 1970;227:680-5.

17 Potasman I, Araujo FG, Desmonts G, et al. Analysis of Toxoplasma gondii antigens recognised by human sera obtained before and after acute infection. F Infect Dis 1986; 154:650-7.

18 Verhofstede C, van Gelder P, Rabaey M. The infectionstage-related IgG response to Toxoplasma gondii studied by immunoblotting. Parasitol Res 1988;74:516-20.

19 Sharma SD, Mullenax J, Araujo FG, et al. Western blot analysis of the antigens of Toxoplasma gondii recognised by human IgM and IgG antibodies. F Immunol 1983;131:97783.

20 Erlich HA, Rodgers G, Vaillancourt P, et al. Identification of an antigen-specific immunoglobulin $M$ antibody associated with acute toxoplasma infection. Infect Immun 1983;41: 683-90.

21 Hellerbrand C, Goebel FD, Disko R. High predictive value of Toxoplasma gondii IgG antibody levels in HIV-infected patients for diagnosis of cerebral toxoplasmosis. Eur $\mathcal{F}$ Clin Microbiol Infect Dis 1996;15:869-72.

22 Hassl A, Aspock H, Flamm H. Circulating antigen of Toxoplasma gondii in patients with AIDS: significance of detection and structural properties. Int $7 \mathrm{Med}$ Microbiol 1988;A271:302-9.

23 Tomavo S, Fortier B, Soete M, et al. Characterization of bradyzoite-specific antigens of Toxoplasma gondii. Infect Immun 1991;59:3750-3.

24 Woodison G, Balfour AH, Smith JE. Sequential reactivity of serum against cyst antigens in Toxoplasma infection. $\mathcal{F}$ Clin Pathol 1993;46:548-50.

25 Ho-Yen DO, Joss AWL, Balfour AH, et al. Use of the polymerase chain reaction to detect Toxoplasma gondii in human blood samples. F Clin Pathol 1992;45:910-3. 